\title{
CTS ou CTSA: O Que (Não) Dizem as Pesquisas sobre Educação Ambiental e Meio Ambiente?
}

\section{STS or STSE: What do the Researches (Dont) Say about Environment and Environmental Education?}

\author{
Rodrigo Luz ; Marcelo Bruno Araújo Queiroz ${ }^{\mathrm{a}}$; Christiana Andréa Vianna Prudêncio ${ }^{\mathrm{b}}$ \\ a Departamento de Ciências Exatas e Tecnológicas, Universidade Estadual de Santa Cruz, Ilhéus, Brasil - \\ rodrigoluz_saj@live.com, bruno.marcelo14@hotmail.com \\ b Departamento de Ciências Biológicas, Universidade Estadual de Santa Cruz, Ilhéus, Brasil - cavprudêncio@uesc.com.br
}

\author{
Palavras-chave: \\ Educação científica. \\ CTSA. Educação \\ ambiental. Meio \\ ambiente. Levantamento.
}

\section{Keywords:}

Scientific sducation. STSE. Environmental education. Environment. Survey.
Resumo: Apresentamos um levantamento referente à produção científica sobre CTS/CTSA existente nos principais periódicos e eventos da área de Educação em Ciências e da Educação Ambiental, no período de 2010 a 2016. Analisamos integralmente 27 trabalhos que se filiam à perspectiva CTSA objetivando verificar os motivos, pressupostos e interesses que marcam a escolha dos pesquisadores por essa denominação, bem como os sentidos que atribuem ao Meio Ambiente e à Educação Ambiental. Diante dos resultados podemos considerar que ainda não existe um consenso na área quanto à compreensão dos pressupostos e características presentes na perspectiva CTSA em comparação à perspectiva CTS, existindo também uma variedade de sentidos atribuídos ao Meio Ambiente. Ademais, existem possibilidades reais de uma produtiva interface com a Educação Ambiental, em que se destacam tendências conservacionistas ou críticas no tratamento das temáticas ambientais presentes nas pesquisas.

\begin{abstract}
We present a survey about the scientific production on STS/STSE existing in the main periodicals and events of the area of Education in Sciences and Environmental Education from 2010 to 2016. We analyzed 27 papers that belong to the STSE perspective, aiming at verifying the reasons, assumptions and interests that mark the choice of researchers for this denomination, as well as the meanings attributed to the Environment and Environmental Education. The results shows that we can consider that there is still no consensus in the area regarding the understanding of the assumptions and characteristics present in the STSE perspective in comparison to the STS perspective, and there is also a variety of meanings attributed to the Environment. Besides, there are real possibilities of a productive interface with the Environmental Education, in which are highlighted tendencies conservationist or critical in the treatment of the environmental themes present in the researches.
\end{abstract}




\section{Introdução}

A necessidade de aproximações entre o campo da Educação em Ciências ${ }^{1}$ (EC) e da Educação Ambiental (EA) é enfatizada por autores (VASCONCELOS, 2003; MARTINS et al., 2008; LOUREIRO; LIMA, 2009; COSENZA; MARTINS, 2011) que investigam possibilidades integradoras capazes de enriquecer a práxis educativa e contribuir para o processo de ressignificação do ensino de Ciências. Para Vasconcelos (2003), o campo da EC aprofundou-se em estudos pedagógicos baseados em diferentes metodologias, enquanto a EA, fortemente influenciada pelos movimentos sociais, teve sua dimensão política fortalecida ao longo do tempo. Sendo assim, os dois campos se complementam na construção de práticas políticopedagógicas que possibilitam um olhar crítico para as questões socioambientais. Esse debate vem sendo intensificado nos últimos anos, especificamente nas revistas de ensino de Ciências, devido à circulação de pesquisas sobre EA nessa área (MARTINS et al., 2008).

Uma das formas de aproximar a EA da EC é por meio da Educação Ciência-TecnologiaSociedade $^{2}$ (CTS), entretanto, as possibilidades de integração ainda não foram investigadas de forma aprofundada. Ambos constituem campos de conhecimento distintos que foram se estabelecendo ao longo da história e adquirindo espaço no âmbito das políticas públicas e da educação, cada um com suas especificidades, seu conjunto de pesquisadores, eventos, periódicos, documentos e livros específicos, entretanto, possuindo similaridades complexas e, muitas vezes, complementares.

A preocupação em articular a EA com a Educação CTS é recente e pouco explorada. Um dos primeiros trabalhos nesse viés foi o de Farias e Freitas (2007). As autoras consideram que as pesquisas nesse âmbito são incipientes, fazendo-se necessárias outras investigações que busquem inter-relacionar essas áreas do saber, que estão pautadas em ideais críticos visando à emancipação do ser no mundo. Além disso, para as autoras, algumas pesquisas consideram essas tendências incompatíveis entre si e as que buscam fazer essa relação permanecem na periferia do problema, havendo, nesse caso, uma superficialidade que pode reforçar utilitarismos no tratamento das questões ambientais (FARIAS; FREITAS, 2007).

No contexto da EC, temos encontrado duas denominações para caracterizar o campo que estuda as inter-relações entre a ciência, a tecnologia e a sociedade: a perspectiva CTS e CTSA. Esta última, adjetivada pela letra "A”, referente a Ambiente, chama atenção para possibilidades

\footnotetext{
${ }^{1}$ Embora a Educação em Ciências seja um campo de conhecimento amplo, neste trabalho focou-se apenas na área das Ciências da Natureza, que contempla Química, Física e Biologia.

2 Utilizamos a denominação "Educação CTS" quando nos referimos aos estudos das relações entre Ciência, Tecnologia e Sociedade na Educação, englobando, assim, o ensino, a aprendizagem, a formação de professores e o currículo. Já "perspectiva CTS/CTSA" é utilizada quando nos referimos a esse campo como uma proposta de reorganização do currículo a partir de temas ou para enfocar outras dimensões, que nem sempre estão presentes no campo educacional, por exemplo, a área das políticas públicas. Utilizamos "Movimento CTS" para nos referirmos à gênese dos estudos CTS, às repercussões históricas desse movimento antes de ser inserido no contexto educacional.
} 
significativas de integração com a EA, uma vez que, para Santos (2007), o movimento CTSA surgiu para que fossem incluídas de forma obrigatória nas inter-relações CTS as questões ambientais, tendo em vista que as discussões na área podem tomar outros direcionamentos que nem sempre compreendem a dimensão ambiental. Nesse sentido, "o movimento CTSA vem resgatar o papel da educação ambiental (EA) do movimento inicial de CTS" (SANTOS, 2007, p. 1).

Apesar disso, a denominação CTSA divide opiniões entre os pesquisadores, com alguns afirmando que a preocupação ambiental é algo inerente ao campo CTS e, portanto, já está implícita na tríade; enquanto outros entendem ser necessário adjetivar esse campo de conhecimento para conferir destaque à dimensão ambiental, historicamente esquecida (SANTOS, 2007, 2012; VILCHES et al., 2011).

Vilches et al. (2011) afirmam que muitos questionam a letra "A" presente na perspectiva CTSA, mas se for dessa forma o próprio termo CTS também deveria ser questionado, visto que a Educação Científica já deveria abranger as discussões referentes à Ciência, à Tecnologia e à Sociedade. Para Loureiro (2012), o processo de adjetivação só deve ocorrer para destacar dimensões esquecidas durante o processo educativo. Nesse sentido, poderíamos, então, afirmar que a Educação CTS deixou de lado a dimensão ambiental privilegiando as discussões ligadas à Ciência, à Tecnologia e à Sociedade? Mas tudo isso também não faria parte do Meio Ambiente?

A pesquisa de levantamento realizada por Abreu et al. (2009) enfatiza que a utilização da perspectiva CTS ou CTSA constitui um debate incipiente num campo em que não há consensos e nem estão evidentes os fundamentos que embasam a perspectiva CTSA em contraste com a perspectiva CTS. Cabe entender se essas abordagens são mutuamente exclusivas, se há motivos para diferenciá-las ou se de fato constituem movimentos distintos (COSENZA; MARTINS, 2011).

O presente trabalho tem a finalidade de tecer contribuições a esse respeito para esclarecer possíveis pontos de conflito e complementaridade entre essas denominações buscando evidenciar as opções que os pesquisadores dos trabalhos analisados assumem, quando se posicionam a favor de uma ou outra nomenclatura. Nesse sentido, nos interessa verificar os motivos, pressupostos e interesses que marcam a escolha dos pesquisadores por essa perspectiva, bem como o sentido que atribuem ao Meio Ambiente e à EA. Dessa forma, elencamos as seguintes questões problematizadoras: que sentido é atribuído ao Meio Ambiente nas pesquisas sobre CTSA? O que existe de EA em articulação com CTSA? Qual vertente da EA está presente? Os trabalhos diferenciam CTS de CTSA? E qual é a ênfase dada à perspectiva CTSA em relação a outras linhas e objetivos de pesquisa existentes?

Essas perguntas são algumas possibilidades de problematização do tema em questão, que podem contribuir para explicitar como os pesquisadores vêm se apropriando dessas ideias 
ao filiarem suas pesquisas no âmbito das relações CTSA e, além disso, colaboram para esclarecer se de fato há ou não necessidade de acrescentar o termo "Ambiente" à tríade CTS.

\section{O caminho da pesquisa}

Inicialmente no campo da EC foram selecionados os periódicos com Qualis A1 ou A2 na área de ensino. Já no campo da EA foram selecionadas as revistas com Qualis A1, A2 e B1 também na área de ensino, levando em consideração que os periódicos da área da EA estão em processo de expansão e, em sua maioria, ainda são qualificados com Qualis B.

Dentro desse critério de classificação, optamos por selecionar as revistas mais representativas da área de EC e EA no contexto brasileiro, com expressivo número de trabalhos publicados sobre as temáticas aqui discutidas. Essas revistas se constituem como importantes meios de divulgação das pesquisas produzidas no meio acadêmico; têm um número considerável de citações nas bases de dados; são amplamente reconhecidas pelos pesquisadores da área, além de na última avaliação da Capes (2016) terem sido classificadas com os estratos mais elevados da qualidade de produção acadêmica.

Foram escolhidos também os dois eventos mais consolidados da área: o Encontro de Pesquisa em Educação Ambiental (EPEA) e o Encontro Nacional de Pesquisa em Educação em Ciências (ENPEC).

O recorte temporal 2010-2016 justifica-se devido ao fato de já haver pesquisas (ABREU et al., 2009, 2013; COSENZA; MARTINS, 2011) que realizaram levantamentos da década de 1980 até 2009 em periódicos da área de EC relacionando CTS-CTSA ou EA-CTS. Embora esses trabalhos não objetivem realizar uma análise conceitual dos campos investigados, neste momento consideraremos essas pesquisas como ponto de partida, pois nos dão indícios de como os campos de conhecimento parecem estar se estruturando ao longo do tempo, e nos permitem aprofundar teoricamente nessas discussões.

Nessa perspectiva, partiremos do ano de 2010 buscando apresentar pesquisas recentes que fazem articulação entre esses campos de conhecimento e nos estenderemos até 2016, ano anterior à realização deste estudo, acrescendo também as pesquisas publicadas em periódicos e eventos da EA. Dessa forma, analisamos dentro do período considerado os seguintes periódicos: Investigações em Ensino de Ciências (IENCI), Alexandria: Revista de Educação em Ciência e Tecnologia, Ciência \& Educação (C\&E), Revista Brasileira de Pesquisa em Educação em Ciências (RBPEC), Ensaio: Pesquisa em Educação em Ciências, Amazônia: Revista de Educação em Ciências e Matemática, Revista Pesquisa em Educação Ambiental (REVIPEA), Revista Eletrônica do Mestrado em Educação Ambiental (REMEA), Educação Ambiental em Ação e Ambiente \& Educação: Revista de Educação Ambiental. Nesses periódicos, 
selecionamos as pesquisas que possuíam no título, resumo e/ou palavras-chave a sigla CTS, CTSA ou sua tradução.

Assim, na categoria CTS, incluímos todas as pesquisas nesse âmbito independentemente de sua filiação temática ou linha de pesquisa adotada. Na categoria CTSA, são incluídas todas as pesquisas que se autodenominam CTSA em vez de CTS. Após a leitura dos resumos foram selecionadas para a análise somente aquelas pesquisas que se filiavam explicitamente à perspectiva CTSA.

Para o estudo aprofundado de cada pesquisa utilizamos a Análise Textual Discursiva (ATD), que, de acordo com Moraes e Galiazzi (2011), apresenta três etapas básicas: 1) unitarização, em que ocorre a desconstrução do corpus, fragmentando-o em unidades de análise. Nesse caso, o corpus consiste nos artigos analisados; 2) categorização, em que essas unidades de significado são relacionadas e agrupadas por suas semelhanças. As categorias produzidas neste trabalho emergiram da análise das unidades de sentidos; e 3) comunicação, em que as categorias produzidas em processo de indução ou dedução possibilitam uma nova compreensão das partes e do todo.

A ATD foi escolhida como ferramenta para a análise dos dados porque permite uma menor rigidez no processo de construção das categorias e possibilita ao pesquisador uma análise subjetiva que vai além do que está aparente nos dados, revelando as verdadeiras intenções presentes no discurso. Ela possibilita também que uma mesma unidade representativa possa ser utilizada em diferentes categorias de acordo com os sentidos que esta consegue expressar (MORAES; GALIAZZI, 2011).

Ressaltamos que apresentamos aqui parte dos resultados de um estudo mais amplo que busca investigar as interfaces, possibilidades e limitações entre a EA e a Educação CTS e CTSA no contexto das principais pesquisas em EC no Brasil. Nossa intenção com esse levantamento não foi abarcar a totalidade do conhecimento existente nas pesquisas, muito menos esgotar o assunto, entretanto, procedemos à análise das pesquisas de forma particular, procurando revelar na essência dos trabalhos unidades de significado presentes no discurso dos pesquisadores que marcam sua opção pela perspectiva CTSA em específico, o que levou à compreensão dos sentidos atribuídos a Meio Ambiente e a EA, bem como os "lugares" que estes ocupam nessas discussões.

\section{Caracterizando a perspectiva CTSA nos eventos e periódicos}

No período de 2010 a 2016 foram publicados 6.540 artigos distribuídos nos periódicos e eventos das áreas de EA e EC que foram selecionados para o desenvolvimento desta pesquisa. Entre os dois eventos e dez periódicos pesquisados no período analisado, foram encontrados 144 artigos sobre CTS e 30 artigos sobre CTSA (Quadro 1). Das 30 publicações que se filiavam 
à perspectiva CTSA, seis pesquisas foram veiculadas em periódicos de EA, enquanto que 24 pesquisas foram veiculadas em revistas de EC e nos anais do ENPEC. No EPEA, não ocorreram publicações sobre CTSA dentro do período considerado.

Quadro $1^{3}$ - Distribuição dos artigos sobre CTS/CTSA em periódicos e eventos de EA e de EC no período de 2010-2016.

\begin{tabular}{|c|c|c|c|c|}
\hline \multirow{2}{*}{ PERIÓDICO } & \multirow{2}{*}{ QUALIS } & \multirow{2}{*}{$\begin{array}{c}\text { Total de artigos } \\
\text { publicados }\end{array}$} & \multicolumn{2}{|c|}{$\begin{array}{c}\text { TOTAL DE ARTIGOS SOBRE } \\
\text { CTS/CTSA }\end{array}$} \\
\cline { 4 - 5 } & & & CTS & CTSA \\
\hline C\&E & $\mathrm{A} 1$ & 405 & 12 & 3 \\
\hline Ensaio & $\mathrm{A} 1$ & 248 & 6 & 0 \\
\hline IENCI & $\mathrm{A} 2$ & 118 & 5 & 1 \\
\hline Alexandria & $\mathrm{A} 2$ & 182 & 17 & 3 \\
\hline RBPEC & $\mathrm{A} 2$ & 223 & 6 & 2 \\
\hline Amazônia & $\mathrm{A} 2$ & 98 & 10 & 0 \\
\hline ENPEC & - & 3526 & 75 & 2 \\
\hline Ambiente \& Educação & $\mathrm{B} 1$ & 140 & 1 & 3 \\
\hline REVIPEA & $\mathrm{B} 1$ & 136 & 0 & 1 \\
\hline REMEA & $\mathrm{B} 1$ & 473 & 3 & 0 \\
\hline Educação Ambiental em Ação & $\mathrm{B} 1$ & 803 & 5 & $\mathbf{3 0}$ \\
\hline EPEA & - & 286 & 3 & $\mathbf{1 4 4}$ \\
\hline
\end{tabular}

Fonte: Dados da pesquisa, 2017.

Considerando a quantidade total de pesquisas publicadas, percebe-se que são poucas as que tratam de CTS e CTSA no período considerado. É possível notar também que a perspectiva CTSA vem sendo assumida tanto por pesquisadores que publicam em periódicos de EA quanto por aqueles que divulgam suas pesquisas em periódicos ou evento específico de EC. Entretanto, a pequena quantidade de pesquisas assumidamente CTSA em comparação com as que se denominam CTS mostra que, de maneira geral, essa denominação ainda vem conquistando espaço junto à comunidade de pesquisadores e permanece em processo de expansão e consolidação. Contudo, é preciso considerar que as pesquisas nesse âmbito ainda são recentes na academia, uma vez que o primeiro artigo sobre CTSA publicado em um periódico no Brasil data de 2006 (ABREU et al., 2009, 2013).

A partir deste momento, nos deteremos nas 30 pesquisas encontradas que fazem referência à CTSA. Entre essas pesquisas, três não foram consideradas para a análise visto que uma delas não discute a perspectiva CTSA, que aparece apenas como um resultado da investigação desenvolvida (NASCIMENTO; REZENDE JUNIOR, 2010); outra adota o termo "CTS/CTSA" não se filiando especificamente a nenhuma das duas nomenclaturas (SOUZA; BRITO, 2015) e, por fim, a terceira pesquisa não pertence ao contexto brasileiro (REES, 2014). Dessa forma, restaram 27 pesquisas (Quadro 2) cujos autores explicitam sua opção em utilizar a perspectiva CTSA de forma evidente. Esses artigos foram sistematicamente lidos na íntegra.

\footnotetext{
${ }^{3}$ As áreas marcadas em cinza se referem a periódicos e a evento específico de EA.
} 
Quadro $2^{4}$ - Descrição dos trabalhos sobre CTSA encontrados em periódicos e eventos de EC e EA no período de 2010-2016.

\begin{tabular}{|c|c|c|c|c|c|c|}
\hline $\begin{array}{l}\text { Trabalho } \\
\text { (T) }\end{array}$ & Autor(es) / Ano & $\begin{array}{l}\text { Gênero das } \\
\text { pesquisas }\end{array}$ & Temática & $\begin{array}{l}\text { Nível de ensino/ } \\
\text { Modalidade da } \\
\text { Educação }\end{array}$ & $\begin{array}{l}\text { Linhas de } \\
\text { pesquisa }\end{array}$ & $\begin{array}{l}\text { Periódico/ } \\
\text { Evento }\end{array}$ \\
\hline T01 & $\begin{array}{l}\text { Monteiro et al. } \\
(2012)\end{array}$ & Empírica & Energia Nuclear & (2) & $\begin{array}{l}\text { Percepção } \\
\text { Ambiental }\end{array}$ & REMEA \\
\hline T02 & Boff et al. (2011) & Empírica & Lixo & Ensino Médio & $\begin{array}{l}\text { Situação de } \\
\text { Estudo }\end{array}$ & REMEA \\
\hline T03 & $\begin{array}{l}\text { Andrade et al. } \\
\qquad(2016)\end{array}$ & Empírica & Agrotóxicos & $\begin{array}{l}\text { Ensino Médio } \\
\text { Profissionalizante }\end{array}$ & $\begin{array}{c}\text { Questões } \\
\text { Sociocientíficas } \\
\text { (QSC) }\end{array}$ & REMEA \\
\hline T04 & Reis et al. (2011) & Empírica & $\begin{array}{l}\text { Mudanças } \\
\text { Climáticas }\end{array}$ & Formação Inicial & QSC & Alexandria \\
\hline T05 & $\begin{array}{c}\text { Trópia et al. } \\
(2013)\end{array}$ & Teórica & Água & - & EA & REVIPEA \\
\hline T06 & $\begin{array}{c}\text { Proença et al. } \\
\text { (2014) }\end{array}$ & Empírica & $\begin{array}{c}\text { Espécies Nativas e } \\
\text { Exóticas }\end{array}$ & $\begin{array}{c}\text { Ensino } \\
\text { Fundamental }\end{array}$ & $\begin{array}{l}\text { Percepção } \\
\text { Ambiental }\end{array}$ & REVIPEA \\
\hline T07 & Ovigli (2011) & Empírica & Água & $\begin{array}{l}\text { Ensino } \\
\text { Fundamental }\end{array}$ & 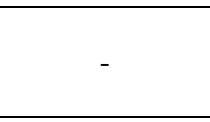 & $\begin{array}{l}\text { Educação } \\
\text { Ambiental } \\
\text { em Ação }\end{array}$ \\
\hline T08 & $\begin{array}{c}\text { Lopes; Carvalho } \\
\text { (2013) }\end{array}$ & Empírica & $\begin{array}{c}\text { Energia e } \\
\text { Desenvolvimento }\end{array}$ & Ensino Médio & QSC & RBPEC \\
\hline T09 & $\begin{array}{c}\text { Paniagua et al. } \\
\text { (2013) }\end{array}$ & Empírica & Energia Nuclear & Ensino Médio & $\begin{array}{l}\text { Perspectiva } \\
\text { Freireana }\end{array}$ & ENPEC \\
\hline $\mathrm{T} 10$ & $\begin{array}{c}\text { Ribeiro; Genovese } \\
(2015)\end{array}$ & Empírica & Múltiplos temas & Ensino Médio & $\begin{array}{c}\text { Ensino por } \\
\text { Pesquisa }\end{array}$ & C\&E \\
\hline $\mathrm{T} 11$ & $\begin{array}{c}\text { Silva; Carvalho } \\
\text { (2012) }\end{array}$ & Empírica & $\begin{array}{c}\text { Temática } \\
\text { Ambiental }\end{array}$ & Formação Inicial & 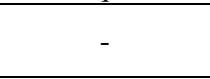 & C\&E \\
\hline $\mathrm{T} 12$ & $\begin{array}{c}\text { Carneiro; Silva } \\
(2011)\end{array}$ & Empírica & - & Formação Inicial & - & ENPEC \\
\hline $\mathrm{T} 13$ & $\begin{array}{c}\text { Araújo; } \\
\text { Formenton (2011) }\end{array}$ & Empírica & $\begin{array}{c}\text { Fontes de energia } \\
\text { automotiva }\end{array}$ & $\begin{array}{c}\text { Educação } \\
\text { Profissional } \\
\end{array}$ & - & ENPEC \\
\hline T14 & $\begin{array}{c}\text { Pessoa; Santos } \\
\text { (2015) }\end{array}$ & Empírica & Ambiente & $\begin{array}{c}\text { Educação de } \\
\text { Jovens e Adultos } \\
\text { (EJA) }\end{array}$ & - & ENPEC \\
\hline $\mathrm{T} 15$ & $\begin{array}{l}\text { Ribeiro et al. } \\
\quad(2011)\end{array}$ & Empírica & Múltiplos temas & Ensino Médio & $\begin{array}{l}\text { Ensino por } \\
\text { Pesquisa }\end{array}$ & ENPEC \\
\hline $\mathrm{T} 16$ & $\begin{array}{l}\text { Santos et al. } \\
(2011)\end{array}$ & Empírica & Energia & $\begin{array}{l}\text { EJA / Ensino } \\
\text { Fundamental }\end{array}$ & $\begin{array}{l}\text { Perspectiva } \\
\text { Freireana }\end{array}$ & ENPEC \\
\hline $\mathrm{T} 17$ & $\begin{array}{c}\text { Santos; Kato } \\
(2013) \\
\end{array}$ & Empírica & Nanotecnologia & $\begin{array}{c}\text { Ensino } \\
\text { Fundamental } \\
\end{array}$ & QSC & ENPEC \\
\hline $\mathrm{T} 18$ & $\begin{array}{c}\text { Ferreira et al. } \\
(2011)\end{array}$ & Empírica & Poluição & $\begin{array}{c}\text { Ensino } \\
\text { Fundamental }\end{array}$ & EA & ENPEC \\
\hline $\mathrm{T} 19$ & Gonzalez (2011) & Empírica & Lixo Urbano & Ensino Médio & EA & ENPEC \\
\hline $\mathrm{T} 20$ & Mion (2011) & $\begin{array}{c}\text { Empírica e } \\
\text { de Revisão } \\
\text { de Literatura }\end{array}$ & $\begin{array}{c}\text { Energia e } \\
\text { Aquecimento } \\
\text { Global }\end{array}$ & $\begin{array}{l}\text { Formação inicial } \\
\text { e Continuada }\end{array}$ & $\begin{array}{c}\text { Professor } \\
\text { Pesquisador/ } \\
\text { Perspectiva } \\
\text { Freireana } \\
\end{array}$ & ENPEC \\
\hline $\mathrm{T} 21$ & $\begin{array}{l}\text { Andrade et al. } \\
\qquad(2015)\end{array}$ & Empírica & Agrotóxicos & $\begin{array}{c}\text { Ensino Médio } \\
\text { Profissionalizante }\end{array}$ & QSC & ENPEC \\
\hline $\mathrm{T} 22$ & $\begin{array}{c}\text { Lopes et al. } \\
(2015)\end{array}$ & Empírica & Agrotóxicos & - & QSC & ENPEC \\
\hline $\mathrm{T} 23$ & Pinto et al. (2013) & Empírica & $\begin{array}{l}\text { Problemas } \\
\text { Ambientais }\end{array}$ & Ensino Médio & QSC & ENPEC \\
\hline $\mathrm{T} 24$ & $\begin{array}{c}\text { Souza et al. } \\
(2015)\end{array}$ & $\begin{array}{c}\text { Revisão de } \\
\text { Literatura }\end{array}$ & - & - & - & ENPEC \\
\hline $\mathrm{T} 25$ & $\begin{array}{c}\text { Siqueira-Batista et } \\
\text { al. }(2010)\end{array}$ & Teórica & $\begin{array}{l}\text { Nanociência e } \\
\text { nanotecnologia }\end{array}$ & - & - & C\&E \\
\hline $\mathrm{T} 26$ & $\begin{array}{c}\text { Lopes; Carvalho } \\
\text { (2012) }\end{array}$ & Empírica & Agrotóxicos & - & QSC & Amazônia \\
\hline $\mathrm{T} 27$ & $\begin{array}{c}\text { Cavalcanti et al. } \\
(2011)\end{array}$ & Empírica & Dengue & Ensino Médio & EA & ENPEC \\
\hline
\end{tabular}

Fonte: Dados da pesquisa, 2017.

${ }^{4}$ Os espaços em branco indicam categoria ausente ou que não se aplicam ao trabalho considerado. 
Começamos a análise classificando as pesquisas em teóricas, empíricas e de revisão de literatura. As pesquisas classificadas como empíricas são aquelas que, além da fundamentação teórica, descrevem procedimentos metodológicos de investigação e/ou intervenção junto a sujeitos, grupos sociais, instituições, comunidades etc. As pesquisas teóricas são os ensaios voltados a discutir pressupostos, características e perspectivas dos campos estudados, evidenciando o posicionamento do pesquisador. Já as pesquisas de revisão de literatura são aquelas que buscam levantar discussões de autores sobre determinada temática ou realizam levantamento sistemático de pesquisas publicadas dentro de certo período nos diferentes meios de divulgação científica.

Assim, constatamos 23 artigos de base empírica, dois teóricos, um de revisão de literatura e um que contempla dois gêneros: revisão e base empírica. As pesquisas empíricas têm prevalência sobre os demais gêneros de pesquisa. Isso pode remeter ao fato de os pesquisadores optarem por construir, em primeira instância, uma caracterização metodológica sobre a perspectiva CTSA, preocupando-se com as questões ligadas à prática e à intervenção propriamente dita.

Entretanto, quase não houve pesquisas teóricas e nem de estado da arte no período considerado. A ausência das últimas é preocupante, tendo em vista que contribuem para situar os diferentes pesquisadores sobre o que vem sendo pesquisado num dado campo de conhecimento, apontando limites e possibilidades e tornando evidente a necessidade ou não de novas investigações. Já a pouca quantidade de pesquisas teóricas pode levar ao entendimento de que os pesquisadores compreendem que os pressupostos da perspectiva CTSA já estão postos no próprio campo CTS e que, portanto, essa nova denominação não carece de mais aprofundamentos teóricos; ou que estão utilizando essa denominação de forma aproblemática e sem o devido rigor analítico, aspectos que buscaremos compreender melhor no decorrer desta pesquisa.

Conforme exposto no Quadro 2, identificamos nos trabalhos analisados uma variedade de linhas de pesquisa que, de diferentes maneiras, estão sendo articuladas com a perspectiva CTSA no âmbito da EC, quais sejam: Situação de Estudo (1), EA ${ }^{5}$ (4), Questões Sociocientíficas (QSC) (8), Perspectiva Freireana (2); Ensino por Pesquisa (2), Percepção Ambiental (2) e Outros (2). Das 27 pesquisas analisadas, 21 utilizam a perspectiva CTSA associada a outras linhas de pesquisa. Isso revela as possibilidades de adequação e relação desse campo de conhecimento com outras linhas de pesquisas, teorias e metodologias presentes no cenário educacional. As temáticas ambientais trabalhadas também são diversas, com destaque para os temas "agrotóxicos" (4) e "energia" (6), que estão presentes em vários trabalhos.

\footnotetext{
${ }^{5}$ A linha de pesquisa EA, embora possa estar presente nos trabalhos sobre CTSA, foi discutida de forma central em quatro artigos, e esse é o motivo desta ser destacada juntamente com outras linhas de pesquisa.
} 
Com relação às pesquisas empíricas, percebemos que as discussões sobre CTSA perpassam diferentes modalidades da educação e níveis de ensino, abrangendo a formação inicial e/ou continuada de professores de Ciências (T04, T11, T14, T20), o Ensino Fundamental (T05, T06, T07, T17, T18), o Ensino Médio (T02, T08, T09, T10, T15, T19, T22, T26; T23; T27); a Educação Profissional (T21, T03; T13); a Educação de Jovens e Adultos (T14; T16) e a Educação Não Formal (T01).

\section{CTS ou CTSA: sentidos e perspectivas}

Em um primeiro momento da análise, investigamos os sentidos atribuídos pelos pesquisadores aos termos "CTS" e "CTSA" e percebemos que estes estão sendo compreendidos e utilizados de quatro formas distintas:

- Como sinônimos: palavras com mesmo significado, podendo ser substituídas sem comprometimento do sentido.

- Como complementares: os termos são assumidos como diferentes em algum aspecto, de modo que pode ocorrer a alternância das abordagens de acordo com o assunto que está sendo discutido. Nesse caso, CTSA pode contribuir com discussões que se referem ao Meio Ambiente complementando a perspectiva CTS.

- CTSA como evolução de CTS: a perspectiva CTSA, ao resgatar questões ambientais para as investigações sobre CTS, acaba superando essa perspectiva e ressignificando-a.

- De forma aproblemática: não são explicitadas diferenças ou semelhanças no uso das denominações CTS e CTSA, nem justificativas de filiação a uma ou outra nomenclatura.

No âmbito da primeira categoria, Como sinônimos, situamos os trabalhos T01, T07, T015, T016, T24, T25 e T26. Para exemplificar, em T01, os autores analisam a percepção socioambiental de um grupo de visitantes de uma exposição temporária sobre energia nuclear. Eles não explicitam os motivos pelos quais utilizam a perspectiva CTSA, dando a entender que fazem isso em termos de realçar aspectos ligados à questão ambiental. Além disso, entendem a perspectiva CTS como sinônimo de CTSA utilizando ideias de pesquisadores que falam sobre a primeira como se estivessem falando sobre a segunda, ou trazendo discussões relacionadas à origem do Movimento CTS como se tratassem da origem da perspectiva CTSA, como nos excertos abaixo:

\footnotetext{
As décadas de 1960 e 1970 são consideradas marcos do pensamento crítico, quando os movimentos contracultura e ambientalista trariam a noção dos limites ambientais do planeta e a necessidade de uma visão menos ingênua do conhecimento científico e tecnológico. Profundamente influenciado por este contexto, e pelas obras de Thomas Kuhn e de Rachel Carson, o pensamento CTSA nasce na comunidade científica [...]. (MONTEIRO et al., 2012, p. 101).
} 
Santos (2008) aponta que a abordagem CTSA de caráter 'reducionista', ao contrário da 'ampliada', se camufla muitas vezes como de enfoque social tendo, entretanto, o intuito de capacitar indivíduos a mensurar custos e benefícios para tomada de decisões, ou seja, a formação para o 'discurso consciente', 'consumo exigente' ou 'saídas tecnológicas’. (MONTEIRO et al., 2012, p. 110).

Percebe-se que não há uma distinção por parte dos autores quanto ao significado dos termos utilizados dentro de uma linha teórica consistente, e tal fato pode servir para reforçar reducionismos e contribuir para a imprecisão terminológica dentro do campo de estudo, com palavras e termos utilizados aleatoriamente e de forma não problematizada. Além disso, essas situações podem reforçar a polissemia existente no campo (STRIEDER; KAWAMURA, 2017), apresentando lacunas no discurso sobre a gênese das perspectivas e sua repercussão no contexto sócio-histórico a qual foi construída.

No âmbito da segunda categoria, CTS e CTSA como complementares, situamos os trabalhos T02, T05, T08, T14, T18, T22, T26 e T27. Destacamos a pesquisa realizada por Trópia et al. (2013) que, à luz da EA e da perspectiva CTSA, analisam um recurso didático utilizado para a avaliação da saúde de rios e lagoas, destinado a estudantes do Ensino Fundamental. Os pesquisadores apostam na complementariedade entre as perspectivas CTS e CTSA, tendo em vista a importância que as discussões socioambientais assumiram no contexto educativo:

No campo das discussões em educação, o enfoque CTS foi apropriado a partir da década de 1980 e, de acordo com Invernizzi e Fraga (2007), foi no processo de adaptação das pesquisas em CTS para o ensino de ciências que a sigla aumentou uma letra, o 'A' (de CTSA) referente ao ambiente. Apesar de não negar que o enfoque CTS já contemplava a questão ambiental, o enfoque CTSA 'vem resgatar o papel da educação ambiental (EA) do movimento inicial de CTS' (SANTOS, 2007, p. 1) e corresponde à 'importância crescente que a dimensão sócio-ambiental [sic] vinha conquistando no sistema de ensino através da Educação Ambiental' (INVERNIZZI; FRAGA, 2007, p. 2). (TRÓPIA et al., 2013, p. 80).

Nessa mesma direção, Pessoa e Santos (2015) investigam os sentidos atribuídos a Meio Ambiente por professores da EJA. As autoras recorrem a uma alternância de termos: ao tratar especificamente de questões relacionadas a temáticas ambientais, utilizam CTSA, mas, quando o assunto é genérico, envolvendo outras discussões, utilizam CTS. Contudo, a perspectiva CTSA é assumida mais incisivamente, ocorrendo com maior frequência ao longo das discussões, conforme explícito nos excertos:

Nesse texto, apresentaremos na sequência aspectos da abordagem CTS que são congruentes com a pesquisa que está em processo, considerações sobre a metodologia e uma análise de um trecho de uma entrevista com uma docente do CEEJA em que se aborda um dos aspectos discutidos nas abordagens CTSA, no caso a contextualização. (PESSOA; SANTOS, 2015, p. 3).

O trabalho como professora coordenadora que busca incentivar os docentes a trabalhar o Currículo oficial de forma contextualizada, como por exemplo, por meio de temas sociais e situações reais (SANTOS, 2007, p. 6) num enfoque CTSA poderá ser facilitado pelo estudo do 'lugar' do entorno da escola e com um olhar para o 
socioambiental, contribuindo assim para a produção de práticas que tragam novos sentidos para todos. (PESSOA; SANTOS, 2015, p. 7).

Percebemos pela via da complementariedade entre as denominações CTS e CTSA certo grau de distinção entre essas perspectivas, com uma complementando o que está ausente ou não tão bem considerado na outra, no que diz respeito à dimensão ambiental e às aproximações com a EA.

Com relação à terceira categoria, CTSA como evolução de CTS, situamos os seguintes trabalhos T06, T09, T19 e T23. Entre eles, destacamos o trabalho T09, em que os autores desenvolvem um projeto sobre energia nuclear com alunos do Ensino Médio, investigando o impacto das atividades didáticas propostas considerando a perspectiva CTSA. Os autores inserem algum nível de distinção entre essas duas nomenclaturas, com a perspectiva CTSA representando uma evolução da perspectiva CTS, conforme exposto a seguir:

Em sua pesquisa Solbes \& Vilches (2004) observaram uma evolução no sentido do chamado enfoque CTSA para o ensino médio de ciências, considerado por muitos como um desdobramento do enfoque CTS (AIKENHEAD, 2003) com ênfase localizada, principalmente, no aspecto ambiental. Segundo essa perspectiva, ao estudarem ciências, os estudantes devem desenvolver competências no sentido de realizarem avaliações sobre riscos e impactos ambientais causados pelos desenvolvimentos científicos e tecnológicos em situações do dia a dia. (PANIAGUA et al., 2013, p. 3).

Essa mesma compreensão pode ser percebida no trabalho de Pinto et al. (2013), que traz a ideia de que a perspectiva CTSA representaria uma ampliação ou evolução da perspectiva CTS:

\begin{abstract}
Nas duas últimas décadas novos estudos em currículos na educação básica e no ensino superior passaram a ter influências da chamada Educação em Ciência, Tecnologia, Sociedade e Ambiente (CTSA), que se mostra como evolução dos Estudos em Ciência, Tecnologia e Sociedade (CTS), sendo que estes últimos tiveram grande "ressonância" a partir de literaturas internacionais, de expoentes como Glen Aikenhead, Joe Salomon, John Ziman entre outros [...]. (PINTO et al., 2013, p. 2).
\end{abstract}

Como podemos perceber, a perspectiva CTSA seria um desdobramento da perspectiva CTS e constituiria a sua superação ou evolução ${ }^{6}$. Nesse sentido, utilizar a denominação CTSA seria optar pelo que há de mais novo e completo nesse campo de estudo, levando a uma compreensão ampliada dos fenômenos científicos, tecnológicos, sociais e ambientais, fugindo de simplismos ou reducionismos.

Com relação aos trabalhos que utilizam CTSA de forma aproblemática (T03, T04, T11, T13, T17, T20, T21), percebemos que os pesquisadores não explicam ou tornam evidente que sentidos têm atribuído ao termo. Temos percebido que essas pesquisas utilizam a perspectiva CTSA apenas para realçar ou justificar o trabalho com alguma temática ambiental. O termo pode fazer parte da discussão ao longo do texto, entretanto, assume papel secundário na

\footnotetext{
${ }^{6}$ A ideia de evolução também pode ser encontrada em Pedretti e Nazir (2011).
} 
pesquisa à medida que não são explicitados seus sentidos, pressupostos ou características. Cuidar da clareza e rigor analítico em pesquisas científicas serve para evitar polissemias, confusões conceituais ou, até mesmo, o uso inapropriado de termos. "Não se trata de defender nominalismos, mas de cuidar da clareza e abrangência do que falamos" (GATTI, 2012, p. 34).

Algo semelhante a isso está relacionado à ênfase conferida à perspectiva CTSA em comparação com outras linhas ou tendências de pesquisa. Identificamos cinco trabalhos (T13, T03, T17, T21, T04) que dizem considerar a perspectiva CTSA em suas investigações utilizando-a apenas como elemento figurativo ou pano de fundo, ou seja, fazendo menção à perspectiva em partes isoladas da pesquisa ou, ainda, conferindo a ela um papel secundário em comparação com outras linhas de pesquisa. Em contrapartida, todos os demais trabalhos analisados nesta pesquisa têm CTSA como eixo estruturante, o que significa que discutem em alguma medida Ciência, Tecnologia, Sociedade e Ambiente no decorrer do texto, ainda que privilegiando alguma dimensão em específico, ou não considerando suas complexas interrelações. Contudo, cabe problematizar em que medida essas discussões de fato consideram o Meio Ambiente, elemento utilizado como fator de diferenciação entre as denominações CTS e CTSA.

Diante dos resultados encontrados, nos parece ser possível afirmar que vêm sendo atribuídos diferentes sentidos à perspectiva CTSA, sugerindo mudanças no trato dessas questões desde as pesquisas de Abreu et al. (2009, 2013), em que os pesquisadores afirmam não haver diferenças significativas quanto aos objetos e interesses dessas denominações. Strieder (2012), ao analisar trabalhos sobre CTS presentes em periódicos da EC, também afirma que as pesquisas que utilizavam a sigla CTSA faziam alusão tanto à CTS quanto à CTSA optando pelo termo "CTS/CTSA", situação pouco encontrada no período considerado nesse levantamento.

\section{Os "lugares" da EA na perspectiva CTSA}

As concepções ambientais estão diretamente relacionadas à maneira como é concebida a EA, campo de conhecimento historicamente voltado ao estudo do Meio Ambiente. A EA constitui atualmente um campo polissêmico formado por uma série de vertentes que foram sendo construídas e apropriadas de formas diversas pelos sujeitos em geral. Essas vertentes podem ser agrupadas em duas macrotendências ampliadas: a EA Conservacionista e a EA Crítica (GUIMARÃES, 2004; LAYRARGUES; LIMA, 2014).

A EA Conservacionista se fundamenta em ações ecológicas que visam minimizar ou atenuar os efeitos antrópicos sobre a natureza, produzindo modificações setoriais na sociedade. Nessa perspectiva, os sujeitos apresentam uma visão ingênua e romântica da realidade, fazendo com que a preocupação da atividade educativa resida na busca por mudanças comportamentais 
individuais, pela preservação e cuidado com a natureza e pelo equilíbrio ecológico (LOUREIRO, 2004; LAYRARGUES; LIMA, 2014).

Já a EA Crítica é revolucionária por essência, buscando inserir os sujeitos em um processo de construção consciente de sua própria história e não adequá-los à estrutura societária imposta. Nessa tendência, são explicitados os mecanismos de dominação existentes na sociedade, bem como os atores sociais que legitimam ideologias, desenvolvem políticas e disseminam práticas opressoras. Os problemas ambientais são enfrentados não apenas no âmbito de seus efeitos, mas na instância em que estão sendo produzidos. Os indivíduos são considerados em sua coletividade, sendo incentivada a luta social organizada (LOUREIRO, 2012).

Entendemos que a EA Crítica integrada à Educação CTS pode contribuir para que temáticas socialmente relevantes e questões ambientais sejam tratadas sob o ponto de vista da complexidade, ampliando os olhares para o Meio Ambiente e suas múltiplas partes constitutivas. Nesse sentido, considerando que, para Santos (2007), a perspectiva CTSA vem resgatar o papel da EA no movimento inicial de CTS, retemos a nossa análise na seguinte questão: o que tem de EA nas pesquisas sobre CTSA?

Passamos, assim, a analisar os "lugares" que a EA ocupa na perspectiva CTSA, percebendo que ela pode aparecer de maneira superficial em CTSA, ou seja, podem ser feitas algumas menções ao termo, ou a outros conceitos que o remetam, sem a problematização desse campo cujos pressupostos se encontram diluídos no texto, conforme está explicitado em vários trabalhos (T02, T03, T04, T07, T08, T09, T10, T12, T14, T15, T16, T17, T21, T23, T25).

A EA ou seus pressupostos também podem aparecer de forma embasada nos trabalhos de CTSA (T01, T05, T06, T11, T18, T19, T27); nesse caso, são citados teóricos da área, aspectos sócio-históricos do campo, além de suas aplicações nas diversas esferas da sociedade como no cenário educativo. Pode tratar-se ainda de uma abordagem pertinente, sensível e crítica da realidade socioambiental ou assumir um viés reducionista, reprodutor e conservador dessa realidade a depender da vertente da EA adotada.

Nas demais pesquisas (T13, T20, T22, T24, T26), não conseguimos identificar elementos ou ideias que remetessem à EA ou ao Meio Ambiente, pois em muitas delas esses termos estão ausentes.

Dessa forma, nos trabalhos que tratam a EA de forma embasada, analisamos a vertente da EA presente. Identificamos que alguns trabalhos (T06, T27) se enquadram em uma tendência conservacionista da EA e do Meio Ambiente. A compreensão reinante está relacionada a mudanças atitudinais e/ou comportamentais dos indivíduos; preservação ambiental; aos problemas que acometem a natureza; aos efeitos da ação antrópica; cuidados com a flora, fauna 
e elementos abióticos; equilíbrio dos ecossistemas etc. No T06, por exemplo, encontramos o seguinte excerto:

\begin{abstract}
Diante da máxima que indica o conhecer para preservar, o currículo do ensino fundamental precisa contemplar a dimensão envolvida na questão da biodiversidade nativa, proporcionando que sejam conhecidas as espécies que se encontram no entorno da escola e da comunidade. Ao priorizar o conhecimento de espécies nativas, tanto da flora e fauna, contribuímos para o maior respeito pela ecologia local, valorizando as vivências diretas com o ambiente natural e chamando a atenção para a valorização de espécies da fauna e da flora da região. (PROENÇA et al., 2014, p. 54-55).
\end{abstract}

Percebe-se no texto a ideia do conhecimento e da preservação como causa e efeito, o que pode levar à compreensão de que basta os indivíduos conhecerem a natureza para preservála, o que não é necessariamente verdade. Assim, sob a ótica de uma EA Conservacionista são colocados em pauta aspectos técnicos e naturais sem a devida problematização da ordem social dominante.

Enquadrando-se em uma perspectiva Crítica da EA, encontramos cinco trabalhos (T01, T05, T11, T18, T19) em que é possível perceber a preocupação em evidenciar as causas que geram as problemáticas ambientais; situando o Meio Ambiente como um campo social formado por atores que lutam pela hegemonia desse campo; considerando o ser humano como um sujeito sócio-historicamente determinado e construtor da própria história e utilizando autores que seguem a tradição crítica da EA. Nesse sentido, a EA se trata de uma educação política, uma vez que "[...] reivindica e prepara os cidadãos e as cidadãs para exigir e construir uma sociedade com justiça social, cidadanias (nacional e planetária), autogestão e ética nas relações sociais e com a natureza" (REIGOTA, 2009, p. 14).

Para exemplificar, destacamos excertos presentes em T01:

Para Lima (2002), o processo de EA que não busque alterar os padrões de distribuição de poder, riqueza, conhecimento, informação e de acesso aos recursos naturais e tecnológicos não pode ser reconhecido em sua autenticidade e legitimidade. (MONTEIRO et al., 2012, p. 103).

Ao encontro desta consideração, Lima (2002) e Loureiro (2006) entendem que o processo educativo da EA crítica deve ser uma ferramenta mais ampla, e que não se restrinja a escolhas racionais, mas contribua a um projeto coletivo que mobilize na direção da mudança política. (MONTEIRO et al., 2012, p. 110).

Dessa forma, pensar e atuar criticamente em EA é entender o Meio Ambiente como um campo social formado por atores que lutam incansavelmente pela hegemonia do campo, transmitindo visões de mundo, valores e crenças e, simultaneamente, produzindo forças capazes de segregar, individualizar e dicotomizar, para que finalmente possa haver dominação (BOURDIEU, 2005).

À luz das análises feitas até aqui, compreendemos que há possibilidades reais de uma produtiva interface entre a EA e a Educação CTS, cujos interesses de pesquisa têm por objeto comum o Meio Ambiente em seus diferentes aspectos. Assim, importa-nos problematizar: que 
sentidos os pesquisadores atribuem ao Meio Ambiente na perspectiva CTSA? Passamos, portanto, a analisar as concepções ambientais presentes nos trabalhos quando essas discussões remetem a assuntos relacionados ao Meio Ambiente e/ou a temáticas socioambientais.

\section{Os sentidos do Meio Ambiente na perspectiva CTSA}

Percebemos que a maioria dos trabalhos que utiliza CTSA não confere ao Meio Ambiente a mesma importância dada às discussões referentes aos outros elementos da tétrade. Entretanto, quando o Meio Ambiente aparece nas pesquisas, vem carregado de sentidos diversos, agrupados aqui em quatro categorias:

- Meio Ambiente natural: compreensão reducionista e ingênua, na qual o Meio Ambiente é considerado como se fosse apenas natureza. Aqui predomina uma ideia romantizada de um Meio Ambiente que necessita ser preservado, cuidado e protegido. Essa concepção é denominada por Reigota (2010) como naturalística, pois prevalecem discussões que tendem a ressaltar apenas os aspectos naturais do Meio Ambiente desconsiderando as outras dimensões que o constituem.

- Meio Ambiente impactado: compreensão que associa o Meio Ambiente a problemáticas ambientais, relacionadas a impactos e ameaças antrópicas. Nessa concepção, podem ser levados em consideração aspectos tecnológicos, científicos e naturais, entretanto, os aspectos naturais são privilegiados, podendo também ser ressaltadas ações de intervenção buscando solucionar ou mitigar os problemas encontrados.

- Meio Ambiente multidimensional: compreensão integrada do Meio Ambiente, que é considerado em suas múltiplas dimensões constitutivas. O Meio Ambiente, nesse caso, é compreendido de forma complexa a partir de uma visão integrada dos processos ecológicos, científicos, tecnológicos, culturais, políticos, históricos e econômicos que determinam a realidade socioambiental.

- Meio Ambiente oculto: não são oferecidos elementos suficientes para a caracterização de como os sujeitos atribuem sentido a esse meio. Isso porque os conceitos e as discussões que remetem a ele podem estar ocorrendo de forma aproblemática e obscura, além do termo "Meio Ambiente" nem mesmo estar presente nos textos.

Essas categorias não obedecem a uma hierarquia, tampouco podemos considerar que existe a "melhor" concepção para o Meio Ambiente. Na verdade, essas diferentes compreensões constituem uma rede de representações ambientais que pode servir a diferentes propósitos no cenário educacional e fora dele. Além disso, em muitos momentos essas compreensões podem se justapor, convergir ou divergir nos discursos dos sujeitos. 
No âmbito da primeira categoria, Meio Ambiente natural, se enquadra o trabalho (T02) em que os autores Boff et al. (2011) desenvolvem uma situação de estudo mobilizando professores da escola e da universidade, bem como estudantes em formação inicial com o objetivo de construir um currículo integrado considerando a perspectiva CTSA. Os autores trabalham especificamente com o tema "lixo" discutindo aspectos ligados ao consumo e destino dos resíduos produzidos pelas pessoas. Quando se referem ao Meio Ambiente, está presente a ideia de que este precisa ser preservado e cuidado, remetendo a uma concepção naturalística:

No entanto, o processo de produção e desenvolvimento da SE [Situação de Estudo]: Ambiente e Vida: o Ser Humano nesse Contexto, envolvendo professores em formação inicial e continuada, na modalidade triádica e estudantes de ensino médio constituiu-se em um espaço privilegiado de apropriação de conhecimentos, habilidades, valores sociais, atitudes e competências voltadas para a preservação do meio ambiente. (BOFF et al., 2011, p. 318-319).

Em Gonzalez (2011), essa concepção ambiental também está presente. A pesquisadora analisa a intervenção sobre lixo urbano realizada por estudantes de licenciatura em Química no Ensino Médio, cuja proposta se fundamenta na EA e nas inter-relações de CTSA. No artigo, encontramos a seguinte afirmação:

\begin{abstract}
A preocupação com o lixo no colégio tornou-se um transtorno ainda maior, quando a escola passou a fornecer merenda aos estudantes o que aumentou consideravelmente os resíduos no interior da mesma. Identificamos, então, que o contexto era propício para o desenvolvimento de propostas pedagógicas que possibilitassem aos educandos a apropriação de conhecimentos e valores, além do desenvolvimento de atitudes necessárias para proteger e melhorar o meio ambiente, uma das finalidades da educação ambiental (EFFTING, 2007). (GONZALEZ, 2011, p. 2).
\end{abstract}

Nos excertos anteriores, é notória a prevalência da compreensão de que o Meio Ambiente precisa ser preservado em seus aspectos puramente naturais. Ressaltamos que o Meio Ambiente também constitui a natureza, entretanto, não pode ser reduzido a ela. Nessa visão romantizada e reducionista são normalmente desconsideradas as demais dimensões que fazem parte da complexidade ambiental (REIGOTA, 2010).

Na segunda categoria, Meio Ambiente Impactado, se enquadram a maioria dos trabalhos aqui analisados (T03, T04, T06, T07, T08, T09, T10, T13, T15, T16, T17, T18, T19, T21, T23, T25). Para evidenciar as semelhanças entre esses trabalhos com relação ao significado que conferem ao Meio Ambiente, destacamos a pesquisa de Santos e Kato (2013) que explora o tema "nanotecnologia" com alunos do Ensino Fundamental numa perspectiva CTSA utilizandose de QSC. Ao longo da pesquisa, percebemos que a Tecnologia assume uma posição central em relação às demais dimensões da tétrade. O Meio Ambiente não é realçado e não assume centralidade na investigação. Quando esse termo aparece, acaba sempre sendo relacionado aos impactos que a Ciência e a Tecnologia podem gerar apenas à dimensão natural que o constitui:

A tecnologia é importante em vários setores como da indústria, cosméticos, informática, alimentação, e na medicina. Alguns exemplos do seu uso estão no desenvolvimento de combustível, no uso de transgênicos, para prevenirmos doenças, 
antes mesmo delas se manifestarem, no rejuvenescimento das células (antiidade) entre outros. Apesar desses benefícios, podemos expor os riscos causados ao meio ambiente, como o desenvolvimento de armas químicas, toxidade e desenvolvimento de câncer entre outros. Enfim, o avanço da tecnologia para a nanotecnologia e seu uso são importantes para a humanidade? Ou trazem riscos para o ambiente e para a espécie humana? Devemos investir nessas pesquisas? (SANTOS; KATO, 2013, p. 3-44).

Concepção semelhante pode ser encontrada em Andrade et al. (2016), que desenvolvem uma pesquisa no âmbito da Educação CTSA, com uma professora e estudantes do Ensino Médio profissionalizante de um município da Bahia, implementando uma sequência didática numa abordagem sociocientífica sobre agrotóxicos:

Segundo Soares e Porto (2012), os agrotóxicos agem no ambiente de duas formas: acumulam-se na biota e contaminam água e solo. [...]. Ainda, uma importante consequência dos agrotóxicos na biota e no solo tem relação com a polinização. Em especial, abelhas polinizadoras têm sido afetadas pelos agrotóxicos, o que tem graves consequências sobre a qualidade e a quantidade de alimentos disponíveis no planeta, por cumprirem importante papel de manter a resiliência dos ecossistemas (STEFFANDEWENTER; POTTS; PACKER, 2005). (ANDRADE et al., 2016, p. 174).

Percebe-se que nesses trabalhos existe uma ênfase na atividade antrópica colocando o ser humano como um ser que age de forma antropocêntrica, desestruturando ecossistemas e causando toda sorte de desequilíbrios. Nessa compreensão, a humanidade faz parte do Meio Ambiente e suas transformações têm contribuído para o estado atual de crise civilizatória que vivenciamos (DIAS, 2004; LOUREIRO, 2004).

Não podemos negar que a quantidade expressiva de trabalhos nessa categoria pode ser uma resposta aos anseios presentes na gênese da própria perspectiva curricular CTS. O livro Silent Spring, da bióloga Rachel Carson, foi uma obra que repercutiu como uma das centralidades do Movimento CTS devido à denúncia ao modelo desenvolvimentista e ao forte impacto ambiental das décadas de 1950 e 1960, principalmente pelo uso do Dicloro-DifenilTricloroetano (DDT). Características históricas que reforçam a concepção de um Meio Ambiente estritamente impactado.

Na terceira categoria, Meio Ambiente Multidimensional, se situam alguns trabalhos (T01, T05, T11, T12 e T14). Destacamos o artigo de Pessoa e Silva (2011) que apresenta as compreensões de licenciandos em Ciências Biológicas sobre as relações CTSA no âmbito de uma disciplina de Geologia ofertada no respectivo curso. Esses autores centram sua análise no Meio Ambiente e mantêm-se nessa direção ao longo de toda a pesquisa. Ocorrem também relações com a Sociedade e a Ciência, entretanto, não são exploradas possibilidades de discussões no âmbito da Tecnologia. Nos excertos a seguir, podemos identificar essa compreensão ambiental:

Em outros momentos do campo já citados nesse trabalho também foi possível perceber a relação que se buscou fazer com as condições políticas, econômicas e sociais que são constitutivas da dinâmica ambiental como, por exemplo, quando se fez o levantamento dos problemas ambientais numa área devastada transformada em aterro e num outro ponto quando se falou do uso e ocupação do solo. Nas aulas ministradas em sala de 
aula alguns aspectos de natureza sócio-político-econômica também foram citados, o que facilitava o entendimento de conteúdos científicos como desmoronamento e perda de inúmeras vidas em áreas de riscos, nascentes de rios quase tocadas pelo asfalto de loteamentos de alto padrão, relação entre diamantes da África do Sul e apartheid, etc. (PESSOA; SILVA, 2011, p. 11).

O trabalho de Silva e Carvalho (2012) também explicita essa concepção integrada para o Meio Ambiente, investigando as compreensões de licenciandos em Física sobre a temática ambiental. Nesse sentido, o trabalho mostra-se bastante coerente com a perspectiva CTSA adotada, uma vez que ao longo do artigo o Meio Ambiente é considerado na tétrade, sendo bastante enfatizado, conforme é possível perceber nos excertos a seguir:

\begin{abstract}
Do mesmo modo, Moraes (2002), ao analisar as concepções dos cientistas sociais sobre a temática ambiental, destaca que uma parte desta é eminentemente tecnicista. Para o autor, concepções dessa natureza colocam em segundo plano a dimensão social da temática ambiental, ao diluírem as implicações políticas de seu manejo - como se as soluções técnicas não envolvessem decisões políticas, interesses, projetos, perspectivas conflitantes etc. (SILVA; CARVALHO, 2012, p. 370).

Porém, o ambiente não é apenas físico, químico ou biológico, do mesmo modo que não é apenas social, histórico e econômico; a temática ambiental envolve o diálogo entre os saberes sistematizados e entre estes e os conhecimentos populares ou do senso comum. Nessa perspectiva, o ambiente é um campo de problematização do conhecimento. (SILVA; CARVALHO, 2012, p. 381).
\end{abstract}

Como vimos, nesses trabalhos está explícita uma compreensão mais complexa do fenômeno ambiental, de maneira a não destacar apenas o problema ou os aspectos da flora e da fauna aí existentes, mas entender a realidade de forma inter-relacionada, dinâmica e integrada. Assim, compreender o Meio Ambiente em sua multidimensionalidade significa percebê-lo integrado com todas as partes constitutivas da realidade que são condição para a existência da complexidade ambiental. Perceber o Meio Ambiente de forma integrada é considerar os aspectos sociais, científicos, tecnológicos, políticos, históricos, culturais e ecológicos não o reduzindo a apenas uma dessas dimensões (LUZ et al., 2017).

Finalmente na última categoria, Meio Ambiente Oculto, situamos os trabalhos T20, T22, T24 e T26. Nesses trabalhos, embora sejam discutidos assuntos e temas que obviamente também fazem parte do Meio Ambiente quando este é entendido em sua complexidade, as discussões desenvolvidas tomam direcionamentos que esvaziam o debate ambiental e acabam não situando os elementos trabalhados como imersos em um Meio Ambiente. A dinâmica socioambiental é desarticulada e as temáticas ambientais, quando trabalhadas, perdem o sentido que poderiam assumir quando inseridas em um contexto ambiental coerente.

\title{
Considerações finais
}

Neste artigo, procuramos verificar os motivos, pressupostos e interesses que marcam a escolha dos pesquisadores pela perspectiva CTSA, bem como os sentidos que atribuem ao Meio Ambiente e à EA. 
Percebemos que há vários sentidos atribuídos ao Meio Ambiente nos trabalhos sobre CTSA, mas que este é normalmente entendido como problema e reduzido a seus aspectos naturais. Além disso, a maioria das pesquisas trata superficialmente o assunto e essa "dimensão" não assume a mesma importância conferida aos outros elementos da tétrade. Acreditamos que isso acontece devido à ausência de um posicionamento direto pela escolha da inclusão da letra "A" na tríade CTS na maior parte das pesquisas e, ainda, que algumas se preocupem em evidenciar a dimensão ambiental e não apresentam uma discussão que sustente a razão pela qual ela não pode ser incluída, por exemplo, na Sociedade. O que percebemos é que, em alguns casos, a simples inclusão de temáticas ambientais em maior ou menor medida é o suficiente para o uso da tétrade.

Entendemos a necessidade de que seja dada a devida atenção às questões socioambientais nas relações CTS. Entretanto, compartilhamos do entendimento de que a denominação CTSA da maneira como está posta não é adequada, pois partimos da compreensão de que situar o Meio Ambiente no mesmo patamar que Ciência, Tecnologia e Sociedade constitui uma compreensão reducionista que desconsidera a complexidade do fenômeno ambiental, reduzindo-o a apenas uma de suas dimensões. Em nosso entendimento, o Meio Ambiente percebido em sua totalidade é capaz de englobar a Ciência, a Tecnologia, a Sociedade e suas múltiplas inter-relações e, portanto, não pode ser reduzido apenas aos aspectos naturais que o constituem e que necessitam ser preservados e protegidos, mas deve ser tratado em toda sua complexidade e integralidade.

Nesse sentido, concordamos com Ricardo (2007) quando este afirma que as soluções não estão presentes nos termos e que estes, ao serem ampliados excessivamente, podem esconder desvios e incoerências no campo teórico e empírico. Essa questão deve ser constantemente discutida, pois do que nos valeria termos como CTSÉtica, CTSArtes, CTSCultura, CTSUrbanismo, sem uma devida discussão?

Assim, é preciso cautela para que não se perpetue de forma acentuada com o campo CTS o que ocorreu com a EA, em que hoje não basta apenas falar em EA, sendo preciso evidenciar que tendência desse campo está sendo seguida, tendo em vista a multiplicidade de correntes pedagógicas e ambientais que baliza os diferentes sujeitos (LAYRARGUES, 2004).

É necessário também combater a ideia de que, ao se trabalhar com a perspectiva CTS ou com questões ambientais, obrigatoriamente já se está trabalhando com a EA. Embora haja muita semelhança entre os campos de conhecimento, eles não são a mesma coisa. Esse discurso tende a esvaziar de sentido a EA, desconsiderando suas peculiaridades teóricas, pressupostos e perspectivas que não foram construídos repentinamente, mas ao longo do desenvolvimento histórico. 
Sugerimos que a Educação CTS, seja seguindo o argumento de que a discussão ambiental está implícita na tríade ou ainda reivindicando a explicitação dessa dimensão por meio da letra "A", busque possibilidades de articulação com a EA, o que sem dúvida enriqueceria de forma significativa as pesquisas e práticas relacionadas a temáticas ambientais e ao Meio Ambiente, sempre que essas discussões se mostrarem pertinentes.

\section{Referências}

ABREU, T. B.; FERNANDES, J. P.; MARTINS, I. Uma análise quantitativa e qualitativa da produção científica sobre CTS (Ciência-tecnologia-sociedade) em periódicos da área de ensino de ciências do Brasil. In: ENCONTRO NACIONAL DE PESQUISA EM EDUCAÇÃO EM CIÊNCIAS, 7., Florianópolis. Anais... Florianópolis, 2009.

ABREU, T. B.; FERNANDES, J. P.; MARTINS, I. Levantamento sobre a produção CTS no Brasil no período de 1980-2008 no campo de ensino de Ciências. Alexandria Revista de Educação em Ciência e Tecnologia, v. 6, n. 2, p. 3-32,2013.

ANDRADE, M. A. S.; ALMEIDA, R. O.; CONRADO, D. M. NUNES-NETO, N. Agrotóxicos e relações CTSA: conhecimentos e atitudes de estudantes de um curso profissionalizante em Agropecuária. In: ENCONTRO NACIONAL DE PESQUISA EM EDUCAÇÃO EM CIÊNCIAS, 10., Águas de Lindoia. Anais... Águas de Lindoia, 2015.

ANDRADE, M. A. S.; CONRADO, D. M.; NUNES-NETO, N. F. ALMEIDA, R. O. Agrotóxicos como questão sociocientífica na Educação CTSA. Rev. Eletrônica Mestr. Educ. Ambient., v. 33, n.1, p. 171-191, 2016.

ARAÚJO, M. S. T.; FORMENTON, R. As fontes de energia automotiva abordadas sob o enfoque CTS em um curso profissionalizante. In: ENCONTRO NACIONAL DE PESQUISA EM EDUCAÇÃO EM CIÊNCIAS, 8., Campinas. Anais... Campinas, 2011.

BOFF, E. T. O.; GOETTEMS, P. B.; PINO, J. P. Ambiente e vida - o ser humano nesse contexto: uma estratégia de ensino transformadora do currículo escolar. Rev. eletrônica Mestr. Educ. Ambient., v. 26, p. 306-321, 2011.

BOURDIEU, P. A economia das trocas simbólicas. 6. ed. São Paulo: Perspectiva, 2005.

CARNEIRO; T. C.; SILVA, H. C. Produção de sentidos sobre CTSA por estudantes de Biologia no contexto de uma disciplina de Geologia. In: ENPEC, 8., Campinas. Anais... Campinas, 2011.

CAVALCANTI, D. B. CHRISPINO, A.; LEMOS, J. L. S.; ANTONIOLI, P. M. Contribuições iniciais de uma unidade didática sobre a dengue articulando Educação Ambiental para a Sustentabilidade e o enfoque CTSA destinada a alunos do Ensino Médio. In: ENCONTRO NACIONAL DE PESQUISA EM EDUCAÇÃO EM CIÊNCIAS, 8., Campinas. Anais... Campinas, 2011.

COSENZA, A.; MARTINS, I. Contribuições da abordagem CTS para a Educação Ambiental: Os "lugares" do ambiente na produção científica sobre CTS. In: EPEA, 6., Ribeirão Preto. Anais... Ribeirão Preto, 2011.

DIAS, G. F. Educação Ambiental: princípios e práticas. 9. ed. São Paulo: Gaia, 2004. 
FARIAS, C. R. O.; FREITAS, D. Educação Ambiental e Relações CTS: uma Perspectiva Integradora. Revista Ciência \& Ensino, n.1, volume especial, 2007.

FERREIRA, D. P.; CHRISPINO, A. ANTONIOLI, P. M. Atitudes dos alunos do ensino fundamental em relação à Ciência, Tecnologia, Sociedade e Ambiente. In: ENCONTRO NACIONAL DE PESQUISA EM EDUCAÇÃO EM CIÊNCIAS, 8., Campinas. Anais... Campinas, 2011.

GATTI, B. A. A construção metodológica da pesquisa em educação: desafios. Revista Brasileira de Política e Administração da Educação, v. 28, n. 1, p. 13-34, 2012.

GONZALEZ, I. M. Análise de um percurso de ensino sobre o lixo urbano na perspectiva CTSA. In: ENCONTRO NACIONAL DE PESQUISA EM EDUCAÇÃO EM CIÊNCIAS, 8., Campinas. Anais... Campinas, 2011.

GUIMARÃES, M. Educação Ambiental Crítica. In: LAYRARGUES, P. P. (cord.)

Identidades da Educação Ambiental Brasileira - Brasília: Ministério do Meio Ambiente, 2004.

LAYRARGUES, P. P. Apresentação: (Re) Conhecendo a Educação Ambiental Brasileira. In: LAYRARGUES, P.P (coord.) Identidades da Educação Ambiental Brasileira, Diretoria de Educação Ambiental; Brasília: Ministério do Meio Ambiente, 2004.

LAYRARGUES, P. P.; LIMA, G. F. C. As macrotendências político-pedagógicas da Educação Ambiental Brasileira. Ambiente \& Sociedade, São Paulo v. 7, n. 1, p. 23-40, 2014.

LOPES, N. C. CARVALHO, W. L. P. Agrotóxicos - toxidade versus custos: uma experiência de formação de professores com as questões sociocientíficas no ensino de ciências. Amazônia Revista de Educação em Ciências e Matemáticas, v. 9, n. 17, p. 27-48, 2012.

LOPES, N. C.; CARVALHO, W. L. P. Possibilidades e Limitações da Prática do Professor na Experiência com a Temática Energia e Desenvolvimento Humano no Ensino de Ciências. Revista Brasileira de Pesquisa em Educação em Ciências, v. 13, n. 2, p. 207-226, 2013.

LOPES, N. C.; CARVALHO, W. L. P.; FARIA, P. C. Agrotóxicos - toxidade versus custos: uma experiência de formação de professores com as questões sociocientíficas no ensino de ciências. In: ENCONTRO NACIONAL DE PESQUISA EM EDUCAÇÃO EM CIÊNCIAS, 10., Águas de Lindoia. Anais... Águas de Lindoia, 2015.

LOUREIRO, C. F. B.; LIMA, J. G. S. Educação ambiental e educação científica na perspectiva Ciência, Tecnologia e Sociedade (CTS): pilares para uma educação crítica. Acta Scientiae, v. 11 n. 1, p. 88-100, 2009.

LOUREIRO, C. F. B. Educação Ambiental Transformadora. In: LAYRARGUES, P. P. (coord.) Identidades da Educação Ambiental Brasileira - Brasília: Ministério do Meio Ambiente, 2004.

LOUREIRO, C. F. B. Trajetórias e Fundamentos da Educação Ambiental. 4. ed. São Paulo: Cortês, 2012.

MARTINS, I.; OLININISKY, M. J.; ABREU, T. B.; SANTOS, L. M. F. Contribuições da análise crítica do discurso para uma reflexão sobre questões do campo da educação ambiental: olhares de educadores de ciências. Pesquisa em Educação Ambiental, v. 3, n. 1, 2008. 
MION, R. A. CTSA na formação do professor e pesquisador e a tradição latino-americana. In: In: ENCONTRO NACIONAL DE PESQUISA EM EDUCAÇÃO EM CIÊNCIAS, 8., Campinas. Anais... Campinas, 2011.

MONTEIRO, R.; SÁNCHEZ, C.; RODRIGUES, C. A percepção socioambiental do público da exposição "energia nuclear" mediante as relações Ciência, Tecnologia, Sociedade e Ambiente: entre a emergência e a armadilha paradigmática. Rev. eletrônica Mestr. Educ. Ambient., v. 28, p. 100-113, 2012.

MORAES, R.; GALIAZZI, M. C. Análise textual discursiva. 2. ed. Ijuí: Unijuí, 2011.

NASCIMENTO, T. G.; REZENDE JUNIOR, M. F. A produção de textos de divulgação científica na formação inicial de licenciandos em ciências naturais. Revista Brasileira de Pesquisa em Educação em Ciências, v. 10, n. 1, p. 1-22, 2010.

OVIGLI, D. F. B. Educação Matemática e realidade socioambiental: uma proposta de trabalho envolvendo o eixo temático grandezas e medidas. Educação Ambiental em Ação, n. 35, v. 9, p. $1-8,2011$.

PANIAGUA, S. K. A.; SILVAS, A. P. R. MACHADO, M. A. D. Energia Nuclear no Ensino Médio: desenvolvendo atividades didáticas com enfoque CTSA - uma possibilidade para a formação da cidadania. In: ENCONTRO NACIONAL DE PESQUISA EM EDUCAÇÃO EM CIÊNCIAS, 10., Águas de Lindoia. Anais... Águas de Lindoia, 2013.

PEDRETTI, E.; NAZIR, J. Currents in STSE education: mapping a complex field, 40 years on. Science Education, v. 95, n. 4, p. 601-626, 2011.

PESSOA, T. C. C.; SANTOS, V. M. N. Deslocamentos de discursos e práticas docentes de professores da EJA (Educação de Jovens e Adultos) considerando-se abordagens CTSA. In: ENCONTRO NACIONAL DE PESQUISA EM EDUCAÇÃO EM CIÊNCIAS, 10., Águas de Lindoia. Anais... Águas de Lindoia, 2015.

PINTO, A. E. A.; ALVES, J. A. P.; MARIA, L. E. LINHARES, M. L. C.; RIBEIRO, L. D. J.; MUCHENSKI, J. C. Investigações sobre relações CTSA e o ensino de Física na visão de estudantes do ensino médio. In: ENCONTRO NACIONAL DE PESQUISA EM EDUCAÇÃO EM CIÊNCIAS, 9., Águas de Lindoia. Anais... Águas de Lindoia, 2013.

PROENÇA, M. S.; OSLAJ, E. U.; DAL-FARRA, R. A. As percepções de estudantes do ensino fundamental em relação às espécies exóticas e o efeito antrópico sobre o ambiente: uma análise com base nos pressupostos da CTSA - Ciência-Tecnologia-Sociedade-Ambiente. Pesquisa em Educação Ambiental, v. 9, n. 2, p. 51-66, 2014.

REES, C. Developing Awareness of Connections Between Science, Technology and the Environment through Participation in a Game-Like Approach to Curriculum. Revista Brasileira de Pesquisa em Educação em Ciências. v. 14, n. 2, p. 147-157, 2014.

REIS, D. A.; SILVA, L. F.; PINA, A. Algumas Compreensões de Licenciandos em Física Sobre o Fenômeno das Mudanças Climáticas. Alexandria - Revista de Educação em Ciência e Tecnologia, v. 4, n. 2, p. 57-81, 2011.

REIGOTA, M. O que é Educação Ambiental? 2. ed. revista e ampliada -São Paulo: Brasiliense, 2009. 
RIBEIRO, T. V.; GENOVESE, L. G. R. O emergir da perspectiva de Ensino por Pesquisa de Núcleos Integrados no contexto da implementação de uma proposta CTSA no Ensino Médio. Ciênc. Educ., v. 21, n. 1, p. 1-29, 2015.

RIBEIRO, T. V. GENOVESE, L. G. R. COLHERINHAS, G. O Ensino Por Pesquisa no Ensino Médio: Discussão de questões CTSA em uma Alfabetização Científico-Tecnológica. In: ENCONTRO NACIONAL DE PESQUISA EM EDUCAÇÃO EM CIÊNCIAS, 8. Campinas. Anais... Campinas, 2011.

RICARDO, E. C. Educação CTSA: obstáculos e possibilidades para sua implementação no contexto escolar. Ciência \& Ensino, v. 1, n. especial, p. 1-12, 2007.

SANTOS, P. G. F.; QUINATO, G. A. C.; OLIVEIRA, E. R. Relações Ciência, Tecnologia, Sociedade e Ambiente (CTSA) em salas de aula de Educação de Jovens e Adultos (EJA): representações e cidadania. In: ENCONTRO NACIONAL DE PESQUISA EM EDUCAÇÃO EM CIÊNCIAS, 8., Campinas. Anais... Campinas, 2011.

SANTOS, I. C. G. M. M.; KATO, D. S. Limites e possibilidades do uso de situações problemas como recurso pedagógico: os temas controversos sócio científicos e as relações CTSA como perspectiva para o ensino de ciências. In: ENCONTRO NACIONAL DE PESQUISA EM EDUCAÇÃO EM CIÊNCIAS, 9., Águas de Lindoia. Anais... Águas de Lindoia, 2013.

SANTOS, W. L. P. Contextualização no ensino de ciências por meio de temas CTS em uma perspectiva crítica. Ciência \& Ensino, v. 1, p. 1-12, 2007.

SANTOS, W. L. P. Educação CTS e Cidadania: Confluências e Diferenças. Amazônia - Revista de Educação em Ciências e Matemáticas, v. 9, p. 49-62, 2012.

SILVA, L. F.; CARVALHO, L. M. A temática ambiental e as diferentes compreensões dos professores de física em formação inicial. Ciência \& Educação, v. 18, n. 2, p. 369-383, 2012.

LUZ, R. S.; SANTANA, U. S.; MONTEIRO, A. S. S.; SANTOS, S. F. C.; CIRQUEIRA, J. S.; ALMEIDA, R. Concepções ambientais dos estudantes do curso de Licenciatura em Biologia da UFRB. Educação Ambiental em Ação, v. 60, p. 1-11, 2017.

SIQUEIRA-BATISTA, R.; MARIA-DA-SILVA, L.; SOUZA, R. R. M.; PIRES-DO-PRADO, H. J.; RÔÇAS, G.; OLIVEIRA, A. L. HELAYËL-NETO, J. A. Nanociência e nanotecnologia como temáticas para discussão de ciência, tecnologia, sociedade e ambiente. Ciência \& Educação, v. 16, n. 2, p. 479-490, 2010.

STRIEDER, R. B. Abordagens CTS na educação científica no Brasil: sentidos e perspectivas. Tese de Doutorado em Ciências/Ensino de Física - Universidade de São Paulo, São Paulo, 2012.

STRIEDER, R. B; KAWAMURA, M. R. D. Educação CTS: parâmetros e propósitos brasileiros. Alexandria: Revista de Educação em Ciência e Tecnologia, v. 10, n. 1, p. 27-56, 2017.

SOUZA, R. G.; BRITO, L. P. Controvérsias em experiências pedagógicas CTS/CTSA na formação inicial de professores de ciências: o que dizem algumas dissertações e teses brasileiras? Amazônia - Revista de Educação em Ciências e Matemática, v. 12, n. 23, p. 85-102, 2015. 
SOUZA, A. C. N.; MESQUITA, D. W. O.; FARIAS, S. A. Reflexões e desafios acerca da abordagem Ciência, Tecnologia, Sociedade e Ambiente na Educação em Ciências/Química na formação do cidadão. In: ENCONTRO NACIONAL DE PESQUISA EM EDUCAÇÃO EM CIÊNCIAS, 10., Águas de Lindoia. Anais... Águas de Lindoia, 2015.

TRÓPIA, G.; VIANA, F. E. C.; GUIMARÃES, A. Q. Análise de discurso ambiental e científico no recurso didático "Protocolo para avaliação da saúde de rios e lagoas", utilizado em projetos de Educação Ambiental em Minas Gerais, Brasil: reflexões a partir do enfoque CTSA. Pesquisa em Educação Ambiental, v. 8, n. 1, p. 76-87, 2013.

VASCONCELOS, M. M. N. A perspectiva crítica aproximando campos da educação ambiental e da educação em ciências. In: ENPEC, 4., Bauru. Anais... Bauru, 2003.

VILCHES, A.; GIL PÉREZ, D.; PRAIA, J. De CTS a CTSA: educação por um futuro sustentável. In: SANTOS, W. L. P.; AULER, D. (Orgs). CTS e educação científica: desafios, tendências e resultados de pesquisas. Brasília: Editora Universidade de Brasília, 2011.

\section{SOBRE OS AUTORES}

RODRIGO DA LUZ SILVA. Licenciado em Biologia pela Universidade Federal do Recôncavo da Bahia - UFRB (2016) e mestrando em Educação em Ciências pela Universidade Estadual de Santa Cruz - UESC. Possui interesse por temáticas associadas à Educação em Ciências, Educação Ambiental e Educação CTS.

MARCELO BRUNO ARAÚJO QUEIROZ. Licenciado em Ciências Biológicas pela Universidade Federal do Piauí - UFPI (2016) e mestrando em Educação em Ciências pela Universidade Estadual de Santa Cruz - UESC. Possui interesse em pesquisas vinculadas à Educação CTS, Educação para Cidadania e Formação de Professores de Ciências/Biologia.

CHRISTIANA ANDRÉA VIANNA PRUDÊNCIO. Mestre e doutora em Educação pela Universidade Federal de São Carlos/SP - UFSCar. Professora adjunta da área de ensino de Biologia da Universidade Estadual de Santa Cruz - UESC e membro permanente do Programa de Pós-Graduação em Educação em Ciências dessa universidade. Pesquisa na área de Formação de Professores de Ciências, Educação CTS e as interfaces entre o Ensino de Ciências e as relações étnico-raciais.

Recebido: 28 de outubro de 2017.

Revisado: 02 de abril de 2018.

Aceito: 12 de junhol de 2018 . 